ISSN : 2615-1995, E-ISSN : 2615-0654

J. Madani., Vol. 4, No. 1, Maret 2021 (45 - 50)

(C)2018 Lembaga Kajian Demokrasi

dan Pemberdayaan Masyarakat (LKD-PM)

DOI: https://doi.org/10.33753/madani.v4i1.155

\title{
Pengaruh Rotasi Kerja, Komunikasi Organisasi, dan Kepuasan Kerja Terhadap Kinerja Karyawan di Kopegtel Jaya
}

\author{
Senen \\ Fakultas Ekonomi, Universitas Pamulang \\ abdisantosasenen@gmail.com
}

\begin{abstract}
Abstrak
Tujuan penelitian ini adalah untuk mengetahui pengaruh secara parsial antara rotasi kerja terhadap kinerja karyawan, unntuk mengetahui pengaruh secara parsial antara komunikasi organisasi terhadap kinerja karyawan, untuk mengetahui pengaruh secara parsial antara kepuasan kerja terhadap kinerja karyawan, untuk mengetahui pengaruh secara simultan antara rotasi kerja, komunikasi organisasi dan kepuasan kerja. Metode dalam penelitian adalah regresi linier berganda, dengan tahapan uji asumsi klasik (normalitas data, multikolinearitas dan heteroskedastisitas), koefisien determinasi, analisis koefisien regresi linier berganda dan uji signifikan ( $t$ dan F). Data yang digunakan adalah data primer dengan cara membagikan kuesioner kepada responden yaitu karyawan KOPEGTEL Jaya yang berjumlah 56 pelanggan. Hasil penelitian menunjukan bahwa bahwa secara parsial variabel rotasi kerja, komunikasi organisasi dan kepuasan kerja berpengaruh terhadap kinerja karyawan. Secara simultan juga menunujukkan bahwa variabel rotasi kerja, komunikasi organisasi dan kepuasan kerja berpengaruh terhadap kinerja karyawan. Berdasarkan hasil koefisien determinasi ditemukan bahwa variabel rotasi kerja, komunikasi organisasi dan kepuasan kerja memiliki pengaruh sebesar 80\%, sedangkan sisanya 20\% dijelaskan dengan faktor atau variabel lain yang tidak diketahui dan tidak termasuk dalam analisis regresi ini, seperti gaji, lingkungan kerja dan lainnya.
\end{abstract}

Kata Kunci : Rotasi Kerja, Komunikasi Organisasi, Kepuasan Kerja, Kinerja Karyawan

\begin{abstract}
The purpose of this study was to know the partial influence between work rotation on employee performance, to know the partial influence between organizational communication on employee performance, to know the partial influence between job satisfaction on employee performance, to know the simultaneous influence between work rotation, organizational communication and job satisfaction. The method in the study was to use multiple linear regression, with classical assumption test stages (data normality, multicolinearity and heteroscedastiity), coefficient of determination, analysis of multiple linear regression coefficients and significant tests ( $t$ and $F$ ). The data used is primary data by distributing questionnaires to respondents, namely KOPEGTEL Jaya employees of 56 customers. The results showed that partially variables of job rotation, organizational communication and job satisfaction affect employee performance. Simultaneously it also shows that variables of job rotation, organizational communication and job satisfaction affect employee performance. Based on the results of the coefficient of determination found that variables of work rotation, organizational communication and job satisfaction have an influence of $80 \%$, while the remaining
\end{abstract}


$20 \%$ is explained by other unknown factors or variables and is not included in this regression analysis, such as salary, work environment and others

Keywords : Job Rotation, Organizational Communication, Job Satisfaction, Employee Performance

\section{PENDAHULUAN}

Peran koperasi sangat penting dan strategis bagi pererkonomian nasional dalam menghadapi persaingan era pasar global saat ini. Era ini merupakan peluang baru untuk dapat mengembangkan pembangunan dan mencapai masyarakat adil dan makmur. Koperasi merupakan badan usaha yang mempunyai landasan konstitusional yang sekaligus sebagai gerakan ekonomi rakyat dengan kualitas dan kemandiriannya merupakan soko guru perekonomian nasional, sehingga diharapkan melalui koperasi pembangunan nasional dan kesejahteraan rakyat dapat ditingkatkan.

Dengan kondisi koperasi di Indonesia saat ini, masyarakat punya kepentingan untuk menyelamatkan dan mengembangkan koperasi di era perdagangan bebas yang akan datang, selain itu pemerintah juga mempunyai kewajiban untuk mengembangkan dan memberikan arahan demi terwujudnya iklim usaha yang sehat demi pembangunan dunia usaha khususnya bagi koperasi maupun bentuk - bentuk usaha lainnya, dengan melalui penciptaan kerangka kebijakan dan peraturan yang mendukung terciptanya iklim usaha yang sehat. Selain itu pembangunan koperasi harus diarahkan, agar koperasi tumbuh menjadi sebuah lembaga usaha yang kuat sekaligus sebagai wadah untuk pembinaan kemampuan ekonomi rakyat, serta mempunyai kegiatan usaha yang didasarkan atas kepentingan para anggota sehingga koperasi dapat memenuhi kebutuhan para anggotanya sekaligus dapat memenuhi kebutuhan masyarakat di lingkungan koperasi.

Secara umum koperasi merupakan suatu badanusaha bersamayang bergerak dalam bidang perekonomian, beranggotakan secara sukarela dan atas dasar persamaan hak, berkewajiban melakukan suatu usaha yang bertujuan untuk memenuhi kebutuhan-kebutuhan para anggotanya. Badan usaha koperasi mempunyai tujuan utama tidak untuk mencari laba tetapi untuk melayani anggota koperasi agar lebih sejahtera dengan berdasarkan asas kekeluargaan. Hal ini juga sudah ditegaskan dengan UUD 45 khususnya pasal 33 ayat 1 yang menyatakan bahwa perekonomian Indonesia disusun sebagai usaha bersama berdasar atas asas kekeluargaan.

Untuk mewujudkan koperasi yang baik perlu ditingkatkan kinerja dari karyawan pada koperasi. Salah satu yang dapat mempengaruhi kinerja adalah rotasi kerja, Setiap karyawan yang memperoleh kesempatan rotasi jabatan maka yang bersangkutan akan memiliki pengetahuan baru, pengalaman baru, wawasan yang luas dan pengayaan keterampilan pada dirinya. Dalam suatu perusahaan terdapat karyawan yang mengalami kejenuhan atau rasa bosan atas pekerjaan yang dilakukannya.

Untuk itu perusahaan dalam hal ini adalah pimpinan harus mempunyai solusi untuk mengatasi hal tersebut, salah satunya adalah dengan melakukan rotasi kerja. Rotasi kerja sendiri merupakan perubahan posisi atau jenis pekerjaan atau wilayah tertentu (Kasmir, 2016:167). Faktor lainnya adalah komunikasi organisasi, Menurut Pace dan Faules (2015:31), komunikasi Organisasi didefinisikan sebagai pertunjukan dan penafsiran pesan di antara unitunit komunikasi yang merupakan bagian dari suatu organisasi tersebut.

Faktor lainnya adalah kepuasan kerja, keadaan emosional yang menyenangkan atau tidak menyenangkan bagi para karyawan memandang pekerjaan mereka. Kepuasan kerja mencerminkan perasaan seseoang terhadap pekerjaannya. Ini tampak dalam sikap positif karyawan tehadap pekerjaan dan segala sesuatu yang dihadapi dilingkungan kerjanya (Sutrisno, 2016).

\section{METODE}

\section{Desain Penelitian}

Penelitian ini merupakan penelitian kuantitatif yang tergolong ke dalam suatu Penelitan kausal. Menurut Sugiyono (2016:19), penelitian kuantitatif dalam melihat hubungan variabel lebih bersifat sebab dan akibat (kausal), sehingga dalam penelitiannya ada variabel independen dan dependen. Dari variabel tersebut selanjutnya dicari seberapa besar pengaruh variabel independen terhadap dependen. 


\section{Populasi dan Sampel}

Adapun penentuan jumlah sampel mengggunakan sampel jenuh, berdasarkan hasil perhitungan sampel sebanyak 56 responden (karyawan) pada KOPEGTEL Jaya. Pengumpulan data dilakukan dengan cara dokumentasi, wawancara dan kuesioner.

\section{Teknik Analisis Data}

Adapun Teknik Analisis Data meliputi Uji Validitas dan Reliabilitas, Uji Asumsi Klasik (Uji Normalitas Data, Uji Multikolinearitas, dan Uji Heteroskedastisitas), Uji Hipotesis (Uji t Parsial dan Uji F Simultan, Koefisien Regresi Linier Berganda, dan Koefisien Determinasi.

\section{HASIL}

\section{Hasil Ujii Valiiditas}

\section{Tabel 1. Hasil Uji Validitas}

\begin{tabular}{|c|c|c|c|}
\hline Item Pertanyaan & $\begin{array}{c}\text { Corrected Item- } \\
\text { Total Correlation } \\
\left(\mathrm{r}_{\text {intuos }}\right)\end{array}$ & Kanbal & Keterangan \\
\hline \multicolumn{4}{|l|}{ Rotasi Kerja $\left(\mathbf{X}_{1}\right)$} \\
\hline RK1 & 0,805 & 0,266 & Valid \\
\hline RK2 & 0,684 & 0,266 & Valid \\
\hline RK3 & 0,702 & 0,266 & Valid \\
\hline RK4 & 0,570 & 0,266 & Valid \\
\hline RKS & 0,721 & 0,266 & Valid \\
\hline RK6 & 0,698 & 0,266 & Valid \\
\hline RK7 & 0,567 & 0,266 & Valid \\
\hline RKS & 0,655 & 0,266 & Valid \\
\hline RKQ & 0,751 & 0,266 & Valid \\
\hline RK10 & 0,590 & 0,266 & Valid \\
\hline \multicolumn{4}{|c|}{ KomunikasiOrganisasi $\left(\mathbf{X}_{2}\right)$} \\
\hline KO1 & 0,729 & 0,266 & Valid \\
\hline KO2 & 0,754 & 0,266 & Valid \\
\hline $\mathrm{KO} 3$ & 0,799 & 0,266 & Valid \\
\hline KO4 & 0,811 & 0,266 & Valid \\
\hline KO5 & 0,592 & 0,266 & Valid \\
\hline KO6 & 0,769 & 0,266 & Valid \\
\hline KO7 & 0,767 & 0,266 & Valid \\
\hline KOS & 0,784 & 0,266 & Valid \\
\hline KO9 & 0,723 & 0,266 & Valid \\
\hline KO10 & 0,715 & 0,266 & Valid \\
\hline \multicolumn{4}{|l|}{ Kepuasan Kerja (Y) } \\
\hline KK1 & 0,542 & 0,266 & Valid \\
\hline KK2 & 0,459 & 0,266 & Valid \\
\hline KK3 & 0,429 & 0,266 & Valid \\
\hline KK4 & 0,651 & 0,266 & Valid \\
\hline KKS & 0,810 & 0,266 & Valid \\
\hline KK6 & 0,417 & 0,266 & Valid \\
\hline KK7 & 0,800 & 0,266 & Valid \\
\hline KKS & 0,522 & 0,266 & Valid \\
\hline KKO & 0,452 & 0,266 & Valid \\
\hline KK10 & 0,430 & 0,266 & Valid \\
\hline \multicolumn{4}{|l|}{ Kinerja Karyawan (Y) } \\
\hline KI1 & 0,542 & 0,266 & Valid \\
\hline $\mathrm{KI} 2$ & 0,459 & 0,266 & Valid \\
\hline $\mathrm{KI} 3$ & 0,429 & 0,266 & Valid \\
\hline KI4 & 0,651 & 0,266 & Valid \\
\hline KI5 & 0,810 & 0,266 & Valid \\
\hline KI6 & 0,417 & 0,266 & Valid \\
\hline $\mathrm{KI} 7$ & 0,800 & 0,266 & Valid \\
\hline KIS & 0,522 & 0,266 & Valid \\
\hline KI9 & 0,452 & 0,266 & Valid \\
\hline KI10 & 0,430 & 0,266 & Valid \\
\hline
\end{tabular}

Dari hasil uji validitas di atas, diperoleh data yang menyatakan bahwa dari item pertanyaan yang diberikan kepada 56 responden ditemukan nilai Corrected Item-Total Correlation (rhitung) lebih besar dari nilai 0,266 (rtabel) yang berarti valid maka dapat dilanjutkan ke penelitian berikutnya.

\section{Hasil Uji Reliabilitas}

Tabel 2. Hasil Uji Reliabilitas

\begin{tabular}{|l|c|c|c|}
\hline \multicolumn{1}{|c|}{ Item Pertanyaan } & $\begin{array}{c}\text { Cronbach's } \\
\text { Alpha }\end{array}$ & $\begin{array}{c}\text { N Of } \\
\text { Item }\end{array}$ & Keterangan \\
\hline Rotasi Kerja $\left(\mathrm{X}_{1}\right)$ & 0,909 & 10 & Reliabel \\
\hline Komunikasi Organisasi $\left(\mathrm{X}_{2}\right)$ & 0,936 & 10 & Reliabel \\
\hline Kepuasan Kerja $\left(\mathrm{X}_{3}\right)$ & 0,865 & 10 & Reliabel \\
\hline Kinerja Karyawan $(\mathrm{Y})$ & 0,906 & 10 & Reliabel \\
\hline
\end{tabular}

Nilai cronbach alpha rotasi kerja $(0,909)$, komunikasi organisasi $(0,936)$, kepuasan kerja $(0,865)$ dan kinerja karyawan $(0,906)$, maka seluruh variabel di atas 0,70 , sehingga dinyatakan reliabel.

\section{Hasil Uji Asumsi Klasik \\ Hasil Uji Normalitas \\ Analisis Grafik}

Normal P.P Plot of Regression Standardized Residual

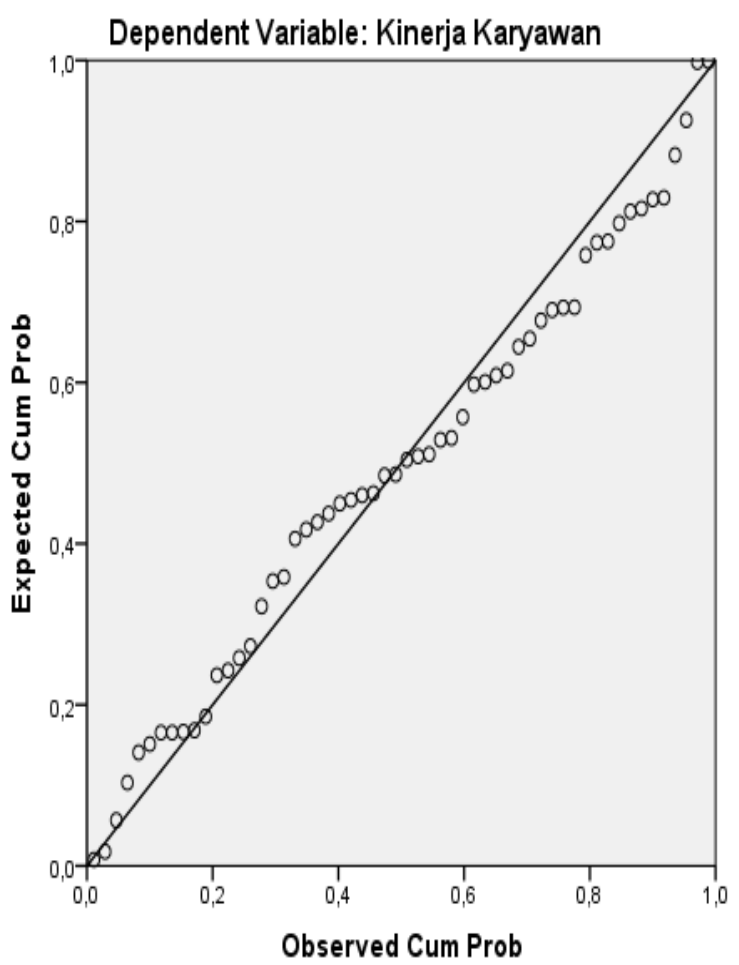

Gambar 1. Normalitas Secara Grafik

Grafik di atas dinyatakan normal, karena titiknya berada mengikuti garis diagonal. 


\section{Analisis Statistik}

Tabel 3. Normalitas Secara Statistik

\begin{tabular}{|l|r|r|}
\hline \multicolumn{2}{|c|}{ One-Sample Kolmogorov-Smirnov Test } \\
\hline N & Mnstandardized Residual \\
\hline Normal Parameters & 56 \\
& Mean & $0 E-7$ \\
& Std. Deviation & .25507439 \\
Most Extreme Differences & Absolute & .092 \\
& Positive & .092 \\
Kolmogorov-Smirnov Z & Negative & .082 \\
Asymp. Sig. (2-tailed) & .691 \\
\hline a. Test distribution is Normal. & .725 \\
\hline b. Calculated from data. & \\
\hline
\end{tabular}

Nilai Asymp. Sig. $(0,725)>0.05$, ini membuktikan data bersifat normal.

\section{Hasil Uji Multikolinearitas}

Tabel 4. Hasil Uji Multikoolinearitas

\begin{tabular}{|c|c|c|c|}
\hline \multicolumn{4}{|c|}{ Coefficients } \\
\hline \multirow{2}{*}{\multicolumn{2}{|c|}{ Model }} & \multicolumn{2}{|c|}{ Collinearity Statistics } \\
\hline & & Tolerance & VIF \\
\hline \multirow{4}{*}{1} & (Constant) & & \\
\hline & Rotasi Keria & 319 & 3.139 \\
\hline & Komunikasi Organisasi & 199 & 5,037 \\
\hline & Kepuasan Keria & 185 & 5.403 \\
\hline
\end{tabular}

Nilai tolerance di atas 0,10 dan nilai VIF di bawah 10, maka dinyatakan tidak terjadi multikolinearitas.

\section{Hasil Uji Heteroskesdastisitas}

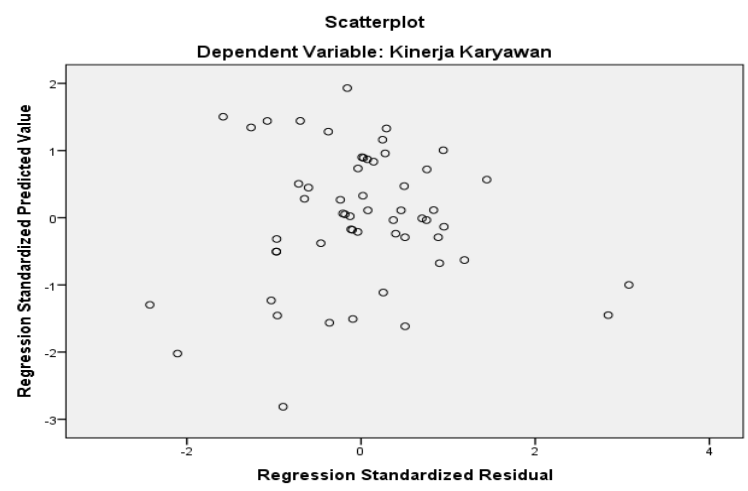

Gambar 2. Heteroskedastisitas

Terlihat bahwa titik-titik menyebar tidak beraturan, tidak mengumpul dan tidak membentuk pola, hal ini menyatakan bahwa tidak terjadi heteroskedastisitas.

\section{Hasil Uji Hiipotesis Peneelitian \\ Hasil Uji t}

Tabel 5. Uji t (Parsial)

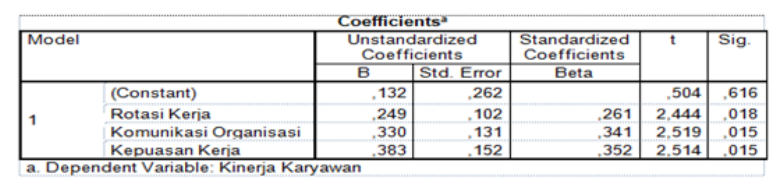

Hasil pengolahan data menyatakan bahwa rotasi kerja, komunikasi organisasi dan kepuasan kerja berpengaruh secara parsial terhadap kinerja karyawan.

\section{Hasil Uji F}

Tabel 6. Uji F (Simultan)

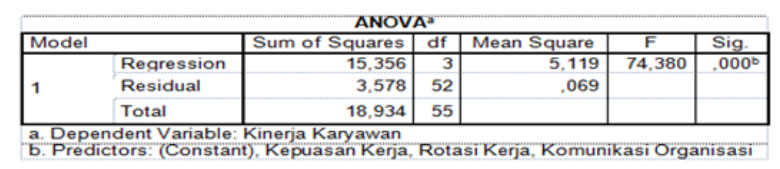

Berdasarkan tabel di atas nilai Fhitung $(74,380)$ lebih besar dari Ftabel $(2,78)$ dan nilai Sig. $(0,000)$ di bawah 0,005 , hal ini membuktikan bahwa rotasi kerja, komunikasi organisasi dan kepuasan kerja berpengaruh secara simultan terhadap kinerja karyawan.

\section{Hasil Koefisien Persamaan Regresi Linier Berganda}

Tabel 7. Hasil Koefisisen Regresi Linier

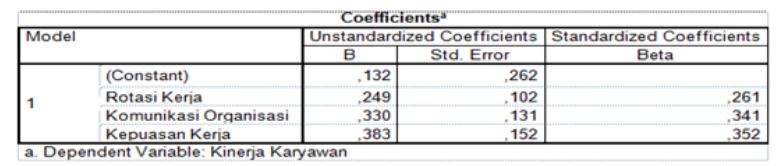

Berdasarkan hasil yang diperoleh dari pekali regresi di atas, persamaan regresi boleh dibuat seperti berikut:

$\mathrm{Y}=0,132+0,249 \mathrm{X} 1+0,330 \mathrm{X} 2+0,383 \mathrm{X} 2$

\section{Hasil Koefisien Determinasi (R2)}

Tabel 8. Hasil Koefisien Determinasi

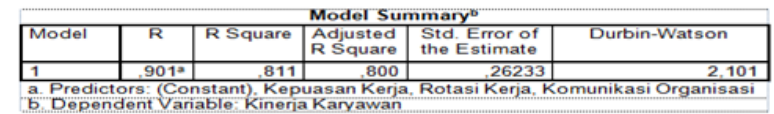


Dari tabel di atas dapat diketahui koefisien determinasi (Adjusdted R Square) sebesar 0,800 atau $80 \%$. Hasil tersebut memberi pengertian bahwa vaiabel dependen yaitu kinerja karyawan dapat dijelaskan oleh variabel independen yang terdiri dari rotasi kerja, komunikasi organisasi dan kepuasan kerja dengan nilai sebesar $80 \%$ sedangkan sisanya $20 \%$ dijelaskan oleh variabel independen lainnya yang tidak dimasukkan dalam model penelitian ini, seperti kompensasi, lingkungan kerja dan lainnya.

\section{PEMBAHASAN}

\section{Pengaruh Rotasi Kerja terhadap Kinerja Karyawan}

Berdasarkan hasil analisis penelitian menunjukkan ada pengaruh positif dan signifikan rotasi kerja terhadap kinerja karyawan. Hal ini membuktikan bahwa semakin baiknya rotasi kerja yang dilakukan perusahaan maka akan semakin baik kinerja karyawan.

Hasil penelitian sesuia dengan penelitian yag dilakukan oleh Sulistiowati Dan Nur (2018), Hasil penelitian menunjukan bahwa rotasi karyawan berpengaruh siginifikan terhadap kinerja karyawan Hotel Rasen Sentani, karena rotasi yang dilakukan dapat memberikan suasana baru, yang bermanfaat untuk menambah pengalaman karyawan dan mencegah kebosanan pada bidang lain, sehingga kinerja karyawan akan lebih meningkat.

\section{Pengaruh Komunikasi Organisasi terhadap Kinerja Karyawan}

Berdasarkan hasil penelitian menunjukkan ada pengaruh positif dan signifikan variabel komunikasi organisasi terhadap kinerja karyawan. Hal ini membuktikan bahwa semakin baiknya komunikasi organisasi yang dilakukan perusahaan maka akan semakin baik kinerja karyawan.

Hasil penelitian sesuai dengan penelitian yang dilakukan oleh Maulida (2018) Hasil pengujian hipotesis yang pertama menunjukkan bahwa komunikasi memiliki pengaruh yang signifikan tehadap kinerja karyawan PT. BESS Finance Banjarmasin, Hasil hipotesis kedua menunjukkan bahwa motivasi memiliki pengaruh yang signifikan terhadap kinerja karyawan PT. BESS Finance Banjarmasin. Hasil hipotesis yang ke tiga menunjukkan bahwa komunikasi dan motivasi secara simultan memiliki pengaruh yang signifikan terhadap kinerja karyawan PT. BESS Finance Banjarmasin.

\section{Pengaruh Kepuasan Kerja terhadap Kinerja Karyawan}

Berdasarkan hasil analisis penelitian menunjukkan ada pengaruh positif dan signifikan kepuasan kerja terhadap kinerja karyawan. Hal ini membuktikan bahwa semakin tingginya tingkat kepuasan kerja karyawan maka akan semakin baik kinerja karyawan.

Hasil penelitian sesuia dengan penelitian yag dilakukan oleh Sari dan Susilo (2018), Hasil penelitian menunjukan kepuasan kerja berpengaruh signifikan terhadap Organizational Citizenship Behavior (OCB). Organizational Citizenship Behavior (OCB) berpengaruh signifikan terhadap kinerja karyawan. Kepuasan kerja berpengaruh signifikan terhadap kineja karyawan. Organizational Citizenship Behavior (OCB) tidak memediasi kepuasan kerja terhadap kinerja karyawan dengan nilai pengaruh langsung yang lebih besar daripada pengaruh tidak langsungnya.

\section{Pengaruh Rotasi Kerja, Komunikasi Organisasi dan Kepuasan Kerja terhadap Kinerja Karyawan}

Berdasarkan hasil analisis penelitian secara simultan menunjukkan ada pengaruh dan signifikan rotasi kerja, komuniasi organisasi dan kepuasan kerja terhadap kinerja karyawan. Besar kontribusi pengaruh antara rotasi kerja, komuniasi organisasi dan kepuasan kerja terhadap kinerja karyawan sebesar $80 \%$ sedangkan sisanya $20 \%$ dijelaskan oleh variabel independen lainnya yang tidak dimasukkan dalam model penelitian ini, seperti kompensasi, lingkungan kerja dan lainnya.

\section{SIMPULAN}

Berdasarkan uji $t$ ditemukan bahwa rotasi kerja berpengaruh terhadap kinerja karyawan. Variabel komunikasi organisasi berpengaruh terhadap kinerja karyawan. Variabel kepuasan kerja berpengaruh terhadap kinerja karyawan. Berdasarkan uji $\mathrm{F}$ (simultan) didapati rotasi kerja, komunikasi organisasi dang kepuasan kerja mempengaruhi kinerja karyawan.

\section{PENGHARGAAN}

Pada kesempatan kali ini penulis ingin mengucapkan terimakasih kepada semua yang terlibat baik secara langsung maupun tidak langsung yang tidak bisa penulis sebutkan satu 
persatu. Terimakasih atas saran, masukan, dan bantuan, semoga penelitian ini bisa bermanfaat bagi semua pihak.

\section{DAFTAR PUSTAKA}

Bangun, W. (2012). Manajemen Sumber Daya Manusia. Jakarta: Erlangga.

Firmansyah, H. (2016). Organisasi dan Manajemen. Yogyakarta: Ombak.

Kartiwi,L. (2016). Pengaruh Rotasi Jabatan dan Teknologi Informasi Terhadap Kinerja Karyawan. Jurnal Manajemen Dan Kewirausahaan, VOL. 1, NO. 2, Mei 2016: 143-151.

Kasmir. (2016). Manajemen Sumber Daya Manusia (Teori dan Praktik). Jakarta: PT Raja Grafindo Persada.

Liliweri, A. (2014). Sosiologi\& Komunikasi Organisasi. Jakarta: Bumi Aksara.

Maulida, N. (2018). Pengaruh Komunikasi Dan Motivasi Terhadap Kinerja Karyawan PT Bess Finance Banjarmasin. Jurnal Ilmiah Manajemen Vol. 2 No. 1 (2018) 12-23.

Najih, A. (2017). Efektivitas Komunikasi Organisasi Pimpinan Dan Kepuasan Kerja Terhadap Kinerja Karyawan Di Universitas Pesantren Tinggi Darul Ulum Jombang. Jurnal Manajemen Dan Pendidikan Islam, Vol. 2, No. 2, Juni 2017; E-ISSN: 2527-6190; P-ISSN: 25033506; Hal. 146-174.

Pace, R., \& Faules. (2015). Komunikasi Organisasi: Strategi Meningkatkan Kinerja. Bandung: PT. Remaja Rosdakarya.
Riani, A. (2013). Perspektif Kompensasi. Surakarta: Yuma Pustaka.

Robbins, S. (2015). Perilaku Organisasi. Jakarta: Salemba Empat.

Romli, \& Syamsul M, A. (2014). Jurnalistik Online: Panduan Mengelola Media. Bandung: Nuansa Cendikia.

Sari, O., \& Susilo, H. (2018). Pengaruh Kepuasan Kerja Terhadap Kinerja Karyawan Dengan Organizational Citizenship Behavior Sebagai Variabel Intervening (Studi pada Karyawan PTPN X - Unit Usaha Pabrik Gula Modjopanggoong Tulungagung). Jurnal Administrasi Bisnis (JAB), Vol. 64, 28 - 35.

Subhki, A., \& Jauhar, M. (2013). Pengantar Teori dan perilaku organisasi,. Jakarta: Prestasi Pustaka Publishe.

Sugiyono. (2016). Metode Penelitian Kuantitatif, Kualitatif dan $R \& D$, . Bandung: PT Alfabet.

Sulistiowati, D., \& Syafei M. N. I. (2018). Pengaruh Rotasi Karyawan Terhadap Kinerja Karyawan Pada Hotel Rasen Sentani Kabupaten Jayapura. Jurnal Future, 2, 75 - 80.

Sutrisno, E. (2016). Manajemen Sumber Daya Manusia, Jakarta: Kencana.

Titisari, P. (2014). Peranan Organizational Citizenship Behavior. Bandung: Mitra Wacana Media

Warsi, D. A. S. (2019). Pengaruh Rotasi Kerja Terhadap Kepuasan Kerja Dalam Mempengaruhi Kinerja Tenaga Kependidikan. Jurnal Ilmiah Akuntansi dan Keuangan, Vol.08, No.01, Tahun 2019. 